\title{
Pecan Preferences Associated with Mid-west Nut Buyers
}

\author{
Julie Campbell \\ Department of Horticulture, University of Georgia, 322 Hoke Smith \\ Building, Athens, GA 30602
}

Vanessa Shonkwiler

Department of Agricultural and Applied Economics, Center for Agribusiness and Economic Development, University of Georgia, 145 Cedar Street, Athens, GA 30602

Additional index words. Carya illinoinensis, conjoint analysis, consumer preferences, pecan, segmentation, tree nuts

\begin{abstract}
Over the past decade, pecans (Carya illinoinensis) have experienced slow to stagnant growth as other nuts see continual growth. Given demand, producers and retailers are needing to finding new ways to market pecans. Using a conjoint experiment with market segmentation, the market for several value-added pecan products (e.g., cinnamon sugar, chocolate-covered, salted and roasted, pralines, and plain roasted) were assessed. Three to four segments within the market were found depending on product size. For a 1.5-oz product, there are three segments (Budget Traditional, Sugar Origin, and Sugar High) that value product attributes differently. The Budget Traditional values plain roasted pecans and has the largest negative reaction to higher prices. The Sugar Origin segment values pralines and chocolate-covered pecans while also valuing Oklahoma- and Texas-produced pecans. The Sugar High segment has a positive preference for chocolate-covered, and pralines and a disdain for cinnamon sugar, salted and roasted, and plain roasted. Examining the 8-oz package size, there are four market segments. The Budget Traditional and Sugar High are similar to the 1.5-oz package size; however, the 8-oz market also has a Price Sensitive segment that highly values low prices as well as a Cinnamon Hater segment that does not like cinnamon sugar pecans. Demographics and past purchasing are key factors for explaining how a consumer is likely to be grouped into segments. Age (i.e., generation) and whether a consumer had purchased nuts within the past year were important indicators across package size.
\end{abstract}

According to the International Nut and Dried Fruit Council (2018), world pecan (C. illinoinensis) production has increased by $28 \%$ over the past decade. An estimated $92 \%$ of pecans are produced in North America, with the United States having $51 \%$ of that production. In 2017, there were 19,008 farms producing 223,903 ha of pecans with $83 \%$ of the hectarage of nut-bearing age [U.S. Department of Agriculture (USDA)-National Agricultural Statistics Service (NASS), 2019b]. Although U.S. production volume has increased by $45 \%$ during the past decade, U.S. pecan production for the 2018-19 marketing season (October-September) was 221.2 million pounds which was a decline of $27 \%$ from the previous year [USDAEconomic Research Service (ERS), 2018; USDA-NASS, 2019a]. Production in 201819 was the lowest level in a decade. The biggest losses were in major pecan-producing

Received for publication 12 May 2020. Accepted for publication 3 Aug. 2020.

Published online 4 September 2020.

J.C. is the corresponding author. E-mail: julie. campbell@uga.edu

This is an open access article distributed under the CC BY-NC-ND license (https://creativecommons. org/licenses/by-nc-nd/4.0/). lower export demand, and increased production levels compared with a decade earlier. As such, producers and retailers have looked to refine factors that drive pecan demand, including varying varieties, sizes, grades, packaging, origin labeling, and use in value-added products. In terms of variety, each of the top four states grow a large amount of "improved" pecan varieties that have been bred and selected for their improved attributes, such as increased yield. However, Oklahoma relies predominately ( $74 \%$ of hectarage) on "native/seedling" varieties compared with the other top states. With respect to consumer preference for pecan varieties, Palma et al. (2015) examined consumer preference for fresh (non-valueadded) pecans. They found consumer preference for native varieties, even though no evidence exists showing native varieties have any additional benefits over improved varieties.

Other studies have examined a myriad of issues associated with pecan consumption to provide pecan growers with knowledge of which attributes are preferred by consumers. Lombardini et al. (2008) and Lillywhite et al. (2014) identified differences in pecan consumers and nonconsumers as well as differences in nutritional knowledge levels. Gold et al. (2004) examined consumer preference for chestnuts (Castanea spp.), walnuts (Juglans spp.), and pecans. Florkowski and Park (2001) examined marketing strategies to enhance sales of raw, unprocessed pecans and evaluated how familiarity of marketing outlets affected consumer purchases of pecans. Moore et al. (2009) found $\$ 0.35$ in additional sales for every dollar invested in the promotion of pecans via the Texas Pecan Checkoff Program. Nelson et al. (2005) found three segments within the Haitian population for honey-roasted pecans. Hinds et al. (2003) compared Haitian consumer views on taste and appearance for Haitian vs. U.S.-produced honey-roasted peanuts.

However, little research has focused on consumer preferences for varying types of value-added pecan products, product origin, or specific farm labeling. Therefore, the main objectives of this experiment were to understand what importance consumers place on various types of value-added pecans (i.e., cinnamon sugar, pralines, salted and roasted, chocolate-covered, and plain roasted), their origins (i.e., Oklahoma, Georgia, Texas, Mexico, and United States), and unique label messaging (i.e., local farm grown, Native American Grown, and no label) when making a purchasing decision. This was done using a conjoint experiment across two package sizes $(1.5 \mathrm{oz}$ and $8 \mathrm{oz}$ ), overall consumer preferences were identified as well as consumer preferences across varying market segments. In addition, demographic and purchasing behaviors were developed for the market segments for the two product sizes examined.

\section{Materials and Methods}

During Oct. 2018, an online survey was administered to Oklahoma, Texas, Arkansas, 
and Kansas residents to better understand consumer preferences and market segments associated with value-added pecan products. Survey participants resided in Oklahoma, Texas, Arkansas, or Kansas. Respondents were recruited from Toluna's (Dallas, TX) database of consumers. Potential respondents within the database, 18 years of age or older and residing in one of the four states listed previously, were contacted via e-mail with a link to the survey. On agreeing to participate in the survey, respondents were asked if they had purchased nuts within the past year. A total of 683 nut purchasers completed the survey. The completion rate for respondents agreeing to participate and answering all questions on entering the survey was $72 \%$.

The sample had a higher median age than the population in the states sampled (Table 1). The sample's median age was 49.5 years, whereas the American Community Survey estimates the U.S. median age as 38.2 years (U.S. Census Bureau, 2019b). However, this is not a direct comparison given the sample did not include persons younger than 18 years. Within the states surveyed, $25 \%$ of the population is younger than 18 (U.S. Census Bureau, 2019a). Removing persons younger than 18 from the Census estimates would bring the Census estimates in-line with the sample's median age. With respect to household income, the sample's median income was $\$ 51,295$ which is similar to Census estimates $(\approx \$ 52,000)$ in the survey states (U.S. Census Bureau, 2019c).

After entering the survey, respondents who had purchased nuts in the past year were asked whether they would be more likely to purchase a value-added pecan product in a $1.5 \mathrm{oz}$ or an $8 \mathrm{oz}$. Sizing was based on standard industry sizing for pecan packaging in this market. After choosing the preferred product size, respondents participated in a conjoint experiment based around their chosen product. Once the conjoint experiment questions were completed, respondents answered nut purchase, demographic, and socioeconomic questions.

Conjoint analysis has been used in a wide array of applications within and outside of agriculture. With respect to applications within agriculture, conjoint analysis has been used to better understand the markets for apples (Baker, 1998, 1999; Baker and Crosbie, 1994; Manalo, 1990; Onozaka and McFadden, 2011), bell peppers (Frank et al., 2001), citrus (Campbell et al., 2004, 2006), peaches (Campbell et al., 2013), strawberries (Darby et al., 2008), tomatoes (Lin et al., 1996; Onozaka and McFadden, 2011), and produce in general (Campbell et al., 2010).

Conjoint analysis is based on random utility theory whereby a consumer's choice of a product is the sum of a consumer's valuation of all attributes characterizing a product (Wirth et al., 2011). This can be represented by

$$
U_{i j}=Z_{i j}+\varepsilon_{i j},
$$

where $U_{i j}$ is a product's total utility for the $i_{t h}$ respondent to the $j_{t h}$ respondent, $\varepsilon_{i j}$ is the stochastic error, and $Z_{i j}$ are the utilities asso-

Table 1. Respondent characteristics for the whole sample and sub-samples of a Midwestern consumer survey on nut preferences.

\begin{tabular}{|c|c|c|c|}
\hline & Total & 1.5 -oz package & 8 -oz packagez \\
\hline Mean age (yr) & 49.5 & 42.9 & 51.8 \\
\hline Median age (yr) & 50.0 & 37.0 & 54.5 \\
\hline \multicolumn{4}{|l|}{ Generation (\%) } \\
\hline Baby Boomer and older & 50 & 32 & 56 \\
\hline Gen $X$ & 32 & 39 & 29 \\
\hline Millennial and younger & 19 & 28 & 15 \\
\hline \multicolumn{4}{|l|}{ State of residence $(\%)$} \\
\hline Texas & 16 & 17 & 15 \\
\hline Kansas & 11 & 10 & 11 \\
\hline Oklahoma & 64 & 68 & 63 \\
\hline Arkansas & 10 & 5 & 11 \\
\hline Gender $(1=$ female $)(\%)$ & 74 & 73 & 74 \\
\hline Primary shopper $(1=$ equal or majority shopper $)(\%)$ & 95 & 94 & 96 \\
\hline Mean household income $(\$)$ & $\$ 51,295$ & $\$ 48,919$ & $\$ 52,101$ \\
\hline Median household income (\$) & $\$ 45,000$ & $\$ 35,000$ & $\$ 45,000$ \\
\hline Race $(1=$ Caucasian $)(\%)$ & 81 & 77 & 82 \\
\hline \multicolumn{4}{|l|}{ Urbanicity (\%) } \\
\hline Rural & 44 & 41 & 45 \\
\hline Urban & 19 & 24 & 17 \\
\hline Suburban & 38 & 35 & 39 \\
\hline Adults in household (18 yr or older) & 2.2 & 2.4 & 2.2 \\
\hline Children in household $(<18 \mathrm{yr})$ & 0.7 & 0.9 & 0.6 \\
\hline \multicolumn{4}{|l|}{ Education (\%) } \\
\hline High school or less & 28 & 33 & 27 \\
\hline Some college/Associates degree & 41 & 38 & 42 \\
\hline Bachelor's degree & 20 & 18 & 21 \\
\hline Higher than Bachelor's degree & 11 & 11 & 11 \\
\hline Body mass index & 29.9 & 29.5 & 30.1 \\
\hline Food neophobia scale index & 31.8 & 33.9 & 31.1 \\
\hline \multicolumn{4}{|l|}{ Purchased nuts within past year (\% yes) } \\
\hline Cashew & 64 & 63 & 65 \\
\hline Almond & 67 & 64 & 68 \\
\hline Peanut & 72 & 72 & 72 \\
\hline Walnut & 45 & 31 & 50 \\
\hline Pecan & 65 & 42 & 72 \\
\hline Hazelnut & 19 & 20 & 18 \\
\hline Other & 8 & 10 & 8 \\
\hline Observations & 683 & 173 & 510 \\
\hline
\end{tabular}

${ }^{2}$ Participants self-selected either a 1.5-oz or an 8-oz package of pecans to evaluate.

ciated with the attributes and corresponding levels that make up the product.

Conjoint analysis experiments require the identification of important attributes and levels. For this study, several attributes were identified as being key drivers to the purchase of value-added pecan products: price, product type, product origin, and label (Table 2). With respect to price, the $1.5-\mathrm{oz}$ and $8-\mathrm{oz}$ packages varied depending on the product size. For the $1.5-\mathrm{oz}$ products, price levels included $\$ 1.29, \$ 1.59$, or $\$ 1.89$ per package. The 8 -oz price levels were $\$ 9.99, \$ 12.49$, or $\$ 14.99$ per package. Product types were the same for the $1.5-\mathrm{oz}$ and $8-\mathrm{oz}$ conjoint experiments: cinnamon sugar, pralines, salted and roasted, chocolate-covered, or plain roasted. For each conjoint profile, both text and a product picture was used to describe the product type. Product origin consisted of five levels: Mexico, United States, Georgia, Oklahoma, or Texas. These areas were chosen because of their importance in pecan production. Finally, value-added labels were tested. These labels were used to better understand consumer response to a specific Oklahoma farm brand (exact farm name not provided in this manuscript due to confidentiality), a generic Native American producer's label, and no label. These labels were important for helping Native American pecan producers to better understand the value and market potential of their products. The specific local farm grown and Native American Grown labels were shown to respondents as a picture within the product profile.

A fractional factorial design was used given it would be unrealistic for respondents to evaluate every combination of the attribute levels. Thereby, respondents evaluated 25 product profiles. A fractional factorial design allows respondents to evaluate a subset of attribute level combinations while maintaining the statistical validity of the design (Hair et al., 2010, p. 411). The order of the product profiles was randomized to limit order bias. For each profile, respondents were asked to indicate their willingness to purchase by clicking anywhere on a continuous line scale, thereby designating $0=$ Definitely would not buy, $50=$ May or may not buy, and $100=$ Definitely would buy. The use of a cardinal rating scale allows the respondent to communicate ordering, indifference, and intensity of how much they like or dislike a product (Fields and Gillespie, 2008; Harrison and Sambidi, 2004).

Ordinary least squares (OLS) regression was used to analyze the data. An individual OLS model was used to identify coefficient 
Table 2. Attributes and levels included in the conjoint experiment for a Midwestern consumer survey on nut preferences.

\begin{tabular}{|c|c|c|c|c|}
\hline \multirow[b]{2}{*}{ Package size } & \multicolumn{4}{|c|}{ Attribute } \\
\hline & Origin & Price per package size & Product & Label \\
\hline \multirow{3}{*}{8 -oz package ${ }^{z}$} & USA & $\$ 12.49$ & Pralines & Native American Grown \\
\hline & Georgia & $\$ 14.99$ & Salted and roasted & No label \\
\hline & Texas & & Plain roasted & \\
\hline \multirow{3}{*}{$1.5-\mathrm{oz}$ package } & Mexico & $\$ 1.29$ & Cinnamon sugar & Specific Local Farm Grown \\
\hline & USA & $\$ 1.59$ & Pralines & Native American Grown \\
\hline & Texas & & Plain roasted & \\
\hline
\end{tabular}

${ }^{\mathrm{z}}$ Participants self-selected either a $1.5-\mathrm{oz}$ or an 8 -oz package of pecans to evaluate.

Table 3. Relative importance and part-worth utilities for each snack model accessed in a Midwestern consumer survey on nut preferences.

\begin{tabular}{|c|c|c|}
\hline & $1.5-\mathrm{oz}$ package ${ }^{\mathrm{z}}$ & 8-oz package \\
\hline \multicolumn{3}{|l|}{$\overline{\text { Relative importance (\%) }}$} \\
\hline Price per package & 12 & 19 \\
\hline Product type & 51 & 44 \\
\hline Product origin & 25 & 26 \\
\hline Label & 12 & 12 \\
\hline \multicolumn{3}{|l|}{ Part-worth utilities ${ }^{y}$} \\
\hline Intercept & 63.74 & 53.87 \\
\hline \multicolumn{3}{|l|}{ Price per product } \\
\hline$\$ 1.29(1.5 \mathrm{oz}), \$ 9.99(8 \mathrm{oz})$ & 0.56 & 5.00 \\
\hline$\$ 1.59(1.5 \mathrm{oz}), \$ 12.49(8 \mathrm{oz})$ & 0.00 & -1.46 \\
\hline$\$ 1.89(1.5 \mathrm{oz}), \$ 14.99(8 \mathrm{oz})$ & -0.56 & -3.54 \\
\hline \multicolumn{3}{|l|}{ Product type } \\
\hline Cinnamon sugar & -4.63 & -6.50 \\
\hline Chocolate-covered & 5.02 & 2.96 \\
\hline Salted and roasted & -0.77 & -0.02 \\
\hline Pralines & 3.45 & 1.21 \\
\hline Plain roasted & -3.08 & 2.36 \\
\hline \multicolumn{3}{|l|}{ Product origin } \\
\hline Oklahoma & 1.69 & 2.62 \\
\hline Georgia & 0.65 & 1.47 \\
\hline Texas & 1.28 & 1.43 \\
\hline Mexico & -4.97 & -7.03 \\
\hline USA & 1.35 & 1.51 \\
\hline \multicolumn{3}{|l|}{ Label } \\
\hline Specific Local Farm Grown & -0.22 & -0.09 \\
\hline Native American Grown & 0.60 & 0.35 \\
\hline No label & -0.39 & -0.26 \\
\hline$R$-squared & $75 \%$ & $76 \%$ \\
\hline Adjusted $R$-squared & $51 \%$ & $53 \%$ \\
\hline Respondents per segment & 173 & 510 \\
\hline
\end{tabular}

${ }^{2}$ Participants self-selected either a 1.5 -oz or an 8-oz package of pecans to evaluate.

${ }^{\mathrm{y}}$ The part-worth utilities can be thought of as the value a consumer places on each attribute level. Positive numbers represent an increase in preference, whereas negative numbers represent a decrease.

estimates (i.e., part-worth utilities) for each respondent. The OLS regression was specified as

$$
Y_{i m}=\beta_{0}+\beta_{i} X_{i j}+\varepsilon_{i j},
$$

where $Y$ is the $i_{t h}$ respondent's rating for the $m_{t h}$ product profile, $\beta_{0}$ is the intercept, $\beta$ is the coefficient estimate (part-worth utility) for the $i_{t h}$ respondent for the $j_{t h}$ attribute level, $X$ is the attribute level viewed in the product profiles, and $\varepsilon$ is the error term. The attribute levels were effects coded that normalize the regression coefficients to "group deviations from the mean of all groups" (Hair et al., 2010, p. 35).

After running the individual-level OLS regressions, the relative importance values were calculated for each individual. Relative importance values represent the amount of not provide valuable marketing recommendations. Therefore, market segments were identified to provide more insights into which products will be accepted in the marketplace. Market segments are created by grouping respondents with similar part-worth utilities into groups (Green and Helsen, 1989). This study used a combination of Ward's method and recommendations by Kotler and Armstrong (2001) to identify the optimal number of market segments within the market. Ward's method identified three and five segments as optimal for both the $1.5-\mathrm{oz}$ and 8-oz models. However, market segments need to be measurable, accessible, substantial, differentiable, and actionable (Kotler and Armstrong, 2001). Based on objective (Ward's method) and subjective (Kotler and Armstrong, 2001) criteria, three segments were chosen for the $1.5-\mathrm{oz}$ model and four segments were chosen for the 8-oz model.

\section{Results}

\section{Total sample}

Across the 1.5-oz and 8-oz conjoint experiments, flavor type of product emerged as the largest factor in a consumer's decision to purchase (Table 3). Within the 1.5-oz sample, this attribute accounted for $51 \%$ of a consumer's buying decision followed by product origin $(25 \%)$, price $(12 \%)$, and label $(12 \%)$. The 8-oz sample results were similar, with price being the only exception. For the 8-oz sample respondents, price was a more important part of their decision-making process (19\%).

Examining part-worth utilities indicated that the results are consistent with economic theory: consumers in both samples valued lower prices to higher prices (Table 3). For example, an average consumer evaluating the 1.5 -oz product increased their rating by 0.56 points on the rating scale when they were shown the $\$ 1.29$ price, while decreasing their rating by 0.56 points when shown the $\$ 1.89$ price. As expected, the consumers evaluating the 8 -oz product were even more averse to higher prices given the increased price magnitude of the larger package. A $\$ 9.99$ price resulted in a 5-point increase in rating, whereas a $\$ 14.99$ price was discounted by 3.54 rating points.

With respect to other attributes, both groups of consumers valued chocolate-covered nuts and pralines more than cinnamon sugar or 
Table 4. Market share breakdown with varying number of market segments of a Midwestern consumer survey on nut preferences.

\begin{tabular}{|c|c|c|c|c|c|c|c|c|}
\hline \# of possible segments & Segment 1 & Segment 2 & Segment 3 & Segment 4 & Segment 5 & Segment 6 & Segment 7 & Segment 8 \\
\hline & \multicolumn{8}{|c|}{ 1.5-oz package ${ }^{z}$ model: Market segments } \\
\hline $3^{y}$ & $42^{x}$ & 29 & 29 & & & & & \\
\hline 4 & 38 & 4 & 29 & 29 & & & & \\
\hline 5 & 38 & 4 & 29 & 20 & 9 & & & \\
\hline 6 & 31 & 6 & 4 & 29 & 20 & 9 & & \\
\hline 7 & 31 & 6 & 4 & 18 & 11 & 20 & & \\
\hline \multirow[t]{2}{*}{8} & 31 & 6 & 4 & 18 & 11 & 5 & 15 & 9 \\
\hline & \multicolumn{8}{|c|}{ 8-oz package ${ }^{z}$ model: Market segments } \\
\hline 3 & 13 & 28 & 59 & & & & & \\
\hline 4 & 13 & 28 & 41 & 18 & & & & \\
\hline 5 & 13 & 28 & 41 & 12 & 6 & & & \\
\hline 6 & 13 & 28 & 33 & 8 & 12 & 6 & & \\
\hline 7 & 13 & 28 & 24 & 9 & 8 & 12 & 6 & \\
\hline 8 & 13 & 17 & 11 & 24 & 9 & 8 & 12 & 6 \\
\hline
\end{tabular}

${ }^{\mathrm{z}}$ Participants self-selected either a 1.5 -oz or an 8-oz package of pecans to evaluate.

${ }^{\mathrm{y}}$ Bold font signifies the best segmentation fit for each packaging model.

${ }^{\mathrm{x}}$ Columns across denote $\%$ of respondents placed in each potential segment.

Table 5. Conjoint results by segment for the 1.5 -oz package size used in a Midwestern consumer survey on nut preferences.

\begin{tabular}{|c|c|c|c|}
\hline & Budget Traditional & Sugar Origin & Sugar High \\
\hline \multicolumn{4}{|l|}{ Relative importance (\%) } \\
\hline Price per $1.5-\mathrm{oz}$ package size & 13 & 14 & 10 \\
\hline Product type & 51 & 38 & 65 \\
\hline Product origin & 23 & 34 & 17 \\
\hline Label & 13 & 14 & 9 \\
\hline \multicolumn{4}{|l|}{ Part-worth utilities ${ }^{\mathrm{z}}$} \\
\hline Intercept & 55.26 & 83.28 & 56.04 \\
\hline \multicolumn{4}{|l|}{ Price per $1.5 \mathrm{oz}$} \\
\hline$\$ 1.29$ & 1.28 & -0.06 & 0.13 \\
\hline$\$ 1.59$ & 0.30 & -0.05 & -0.37 \\
\hline$\$ 1.89$ & -1.59 & 0.11 & 0.25 \\
\hline \multicolumn{4}{|l|}{ Product type } \\
\hline Cinnamon sugar & -1.60 & 0.56 & -14.28 \\
\hline Chocolate-covered & -4.24 & 3.91 & 19.50 \\
\hline Salted and roasted & 7.93 & -3.29 & -10.71 \\
\hline Pralines & -6.24 & 4.05 & 16.79 \\
\hline Plain roasted & 4.16 & -5.24 & -11.30 \\
\hline \multicolumn{4}{|l|}{ Product origin } \\
\hline Oklahoma & 0.99 & 5.61 & -1.31 \\
\hline Georgia & 0.70 & 0.43 & 0.80 \\
\hline Texas & 1.22 & 2.19 & 0.45 \\
\hline Mexico & -3.15 & -11.32 & -1.13 \\
\hline USA & 0.23 & 3.09 & 1.18 \\
\hline \multicolumn{4}{|l|}{ Label } \\
\hline Specific Local Farm Grown & -0.04 & 0.32 & -1.02 \\
\hline Native American Grown & 0.40 & 0.58 & 0.92 \\
\hline No label & -0.36 & -0.90 & 0.09 \\
\hline$R$-squared (\%) & 73 & 69 & 86 \\
\hline Adjusted $R$-squared (\%) & 45 & 38 & 71 \\
\hline Respondents per segment & 72 & 51 & 50 \\
\hline Market share (\%) & 42 & 29 & 29 \\
\hline
\end{tabular}

${ }^{\mathrm{z}}$ The part-worth utilities can be thought of as the value a consumer places on each attribute level. Positive numbers represent an increase in preference, whereas negative numbers represent a decrease.

salted/roasted. However, the 8-oz sample had a positive valuation of plain roasted compared with the negative valuation for the 1.5 oz sample. Respondents of both samples had positive values for all origins except the imported label (Mexico). Both samples preferred the Native American Grown label as opposed to no label or the specific local farm grown label.

\section{Market segmentation}

Using statistical techniques (i.e., Ward's for this paper) to identify the optimal number of market segments without examining the underlying structure of the market segments fails to assess valuable information for product development (Table 4). The Ward method identified three segments for the 1.5-oz buying group and four segments for the 8-oz buying group as the optimal groupings within the value-added nut market. In both models, several segments remain fairly constant as additional segments are added. Moving from three to four segments in the $1.5-\mathrm{oz}$ model, segments two and three stay constant and $4 \%$ of segment one form a new segment. As the segments increase in number, new segments are formed but the three original segments keep a majority of their members. The remaining segments are smaller and do not satisfy the Kotler and Armstrong (2001) criteria. Similarly, the four segments identified for the $8 \mathrm{oz}$ maintain the majority of their members until much larger segment numbers are added, thereby violating the Kotler and Armstrong (2001) criteria.

From the results in Table 4, the use of three segments (1.5-oz model) and four segments (8-oz model) are capturing the major differences in preferences within the sample. If there were major shifts in preference structure when adding additional market segments, then the findings would be less robust as the merging of segments with different preferences could cause incorrect recommendations. However, given the underlying preference structure remained the same for most segments with the final segments being split into small segments has increased confidence in the results.

\section{Conjoint and segmentation results: 1.5- oz sample}

The three segments in the $1.5-\mathrm{oz}$ sample were classified as "Budget Traditional," "Sugar Origin," and "Sugar High" given the relative importance values and part-worth utilities associated with these (Table 5). All three segments valued product type the most followed by product origin, price, and label. The main differences were as follows: Sugar Origin valued product type nearly as much as product origin (relative importance: $38 \%$ vs. $34 \%$ ), the Budget Traditional segment valued product type the most (relative importance: $51 \%$ ) but also had the largest price differences within the partworth utilities, and Sugar High had the highest relative importance associated with product type (65\%).

Budget Traditional. The Budget Traditional segment was the largest segment at $42 \%$ of the market (Table 5). This segment attached positive utilities to salted and roasted and plain roasted nuts, while discounting cinnamon sugar, pralines, and chocolate-covered nuts (Table 5). The salted and roasted nuts received a 7.93-point rating increase, whereas plain roasted had a 4.16point rating increase on the 100 -point scale. 
Table 6. Multinomial logit results for the 1.5-oz package size used in a Midwestern consumer survey on nut preferences.

\begin{tabular}{|c|c|c|c|c|c|c|}
\hline & \multicolumn{2}{|c|}{ Budget Traditional } & \multicolumn{2}{|c|}{ Sugar Origin } & \multicolumn{2}{|c|}{ Sugar High } \\
\hline & Coeff. & $P$ value & Coeff. & $P$ value & Coeff. & $P$ value \\
\hline \multicolumn{7}{|l|}{ Generation } \\
\hline Baby Boomer and older & $-0.194^{z}$ & 0.091 & 0.231 & 0.037 & -0.038 & 0.719 \\
\hline Gen X & - & - & - & - & - & - \\
\hline Millennial and younger & -0.060 & 0.617 & 0.012 & 0.915 & 0.049 & 0.649 \\
\hline \multicolumn{7}{|l|}{ State of residence } \\
\hline Texas & -0.023 & 0.856 & 0.043 & 0.689 & -0.020 & 0.863 \\
\hline Kansas & 0.516 & 0.000 & -0.295 & 0.000 & -0.221 & 0.005 \\
\hline Oklahoma & - & - & - & - & - & - \\
\hline Arkansas & -0.065 & 0.753 & 0.088 & 0.639 & -0.023 & 0.899 \\
\hline Gender $(1=$ female $)$ & -0.044 & 0.697 & -0.038 & 0.696 & 0.082 & 0.377 \\
\hline Primary shopper $(1=$ equal or majority shopper $)$ & 0.271 & 0.071 & 0.003 & 0.986 & -0.274 & 0.172 \\
\hline Mean household income $(\$)$ & 0.000 & 0.972 & 0.000 & 0.535 & 0.000 & 0.587 \\
\hline Race $(1$ = Caucasian $)$ & -0.002 & 0.988 & 0.001 & 0.988 & 0.000 & 0.997 \\
\hline \multicolumn{7}{|l|}{ Urbanicity } \\
\hline Rural & 0.183 & 0.124 & -0.099 & 0.316 & -0.084 & 0.402 \\
\hline Urban & - & - & - & - & - & - \\
\hline Suburban & -0.029 & 0.819 & 0.094 & 0.396 & -0.066 & 0.521 \\
\hline Adults in household (18 yr or older) & -0.020 & 0.609 & 0.018 & 0.601 & 0.002 & 0.949 \\
\hline Children in household (<18 yr) & -0.012 & 0.800 & 0.015 & 0.702 & -0.004 & 0.926 \\
\hline \multicolumn{7}{|l|}{ Education } \\
\hline High school or less & 0.030 & 0.841 & 0.070 & 0.618 & -0.100 & 0.380 \\
\hline Some college/Associate's degree & 0.108 & 0.434 & 0.035 & 0.779 & -0.143 & 0.180 \\
\hline Bachelor's degree & - & - & - & - & - & - \\
\hline Higher than Bachelor's degree & -0.159 & 0.362 & 0.387 & 0.039 & -0.227 & 0.010 \\
\hline Body mass index & -0.003 & 0.522 & -0.001 & 0.890 & 0.004 & 0.392 \\
\hline Food neophobia scale index & 0.001 & 0.811 & -0.002 & 0.656 & 0.001 & 0.859 \\
\hline \multicolumn{7}{|l|}{ Purchased nuts within past year } \\
\hline Cashew & -0.218 & 0.043 & 0.068 & 0.440 & 0.150 & 0.084 \\
\hline Almond & -0.067 & 0.505 & -0.034 & 0.689 & 0.101 & 0.213 \\
\hline Peanut & -0.175 & 0.097 & 0.062 & 0.461 & 0.113 & 0.179 \\
\hline Walnut & 0.206 & 0.065 & $-\mathbf{0 . 1 5 3}$ & 0.062 & -0.053 & 0.586 \\
\hline Pecan & 0.189 & 0.093 & 0.087 & 0.367 & -0.275 & 0.003 \\
\hline Hazelnut & -0.101 & 0.419 & -0.020 & 0.857 & 0.121 & 0.361 \\
\hline Other & 0.162 & 0.333 & -0.203 & 0.016 & 0.041 & 0.794 \\
\hline Observations & \multicolumn{6}{|c|}{173.000} \\
\hline Likelihood ratio $\chi^{2}$ & \multicolumn{6}{|c|}{60.420} \\
\hline Prob. $>\chi^{2}$ & \multicolumn{6}{|c|}{0.149} \\
\hline Pseudo $r^{2}$ & \multicolumn{6}{|c|}{0.161} \\
\hline
\end{tabular}

${ }^{\mathrm{z}}$ Bold denotes significance at the 0.1 level or less.

This equates to a $7.93 \%$ and $4.16 \%$ increase in rating for these two nut products. On the other hand, pralines were rated 6.24 points lower. With respect to product origin, the Budget Traditional segment valued Texas product (1.22 utility increase) followed closely by Oklahoma ( 0.99 utility increase) and Georgia ( 0.70 utility increase). Mexican imports were discounted by 3.15 points. In addition, this segment preferred the Native American Grown label (0.40 utility increase) with virtually no impact for the specific local farm grown label ( -0.04 utility decrease).

With respect to the demographic make-up of the segments, the Budget Traditional segment was less likely to comprise Baby Boomer and older consumers (compared with Generation $\mathrm{X}$ ), while being more likely to be from Kansas (compared with Oklahoma) and primary shoppers (Table 6). Notably, Baby Boomers and older were $19.4 \%$ less likely than Generation $\mathrm{X}$ respondents to be in this segment, but primary shoppers were $27.1 \%$ more likely to be in this segment. Examining nut purchasing results in findings that purchasers of cashews (Anacardium occidentale) and peanuts (Arachis hypogaea) were $21.8 \%$ and $17.5 \%$ less likely to be in this segment com- pared with nonpurchasers of these nuts, respectively. On the other hand, walnut and pecan purchasers were $20.6 \%$ and $18.9 \%$ more likely to be in this segment, respectively.

Sugar Origin. The Sugar Origin segment highly valued chocolate-covered (3.91 utility increase) and pralines (4.05 utility increase), while giving a negative utility to salted and roasted and plain roasted (Table 5). This segment also highly discounted Mexican product $(-11.32$ utility decrease), while valuing Oklahoma (5.61 utility increase), United States (3.09 utility increase), and Texas (2.19 utility increase) products. This segment was the only segment to have a positive preference for both the specific local farm grown (0.32 utility increase) and Native American Grown ( 0.58 utility increase) labels.

Baby Boomers and older were $23.1 \%$ more likely than Generation X respondents to be in this segment, whereas more educated respondents, those with more than a Bachelor's degree, were $38.7 \%$ more likely to be in the segment compared with respondents with a Bachelor's degree (Table 6). Walnut and other nut buyers were $15.3 \%$ and $20.3 \%$ less likely be in this segment than nonbuyers of these nuts, respectively.

Sugar High. The Sugar High segment highly valued chocolate-covered nuts and pra- lines (Table 5). Notably, chocolate-covered nuts raised a respondent's utility for the product by 19.50 points, whereas pralines increased the utility by 16.79 points. However, cinnamon sugar (-14.28 utility decrease), salted and roasted (-10.71 utility decrease), and plain roasted ( -11.30 utility decrease) considerably reduced this segment's utility for the product. Further, this segment valued the USA label more than the state origins. However, this is the only segment that had a negative preference for the Oklahoma origin $(-1.31$ utility decrease). With respect to labels, the Sugar High segment had high utility for the Native American Grown label and a negative utility for the specific local farm grown label.

Kansas respondents were $22.1 \%$ less likely than Oklahoma respondents to be in this segment (Table 6). Given this segment has a negative utility for the Oklahoma origin, one would have suspected that this segment would have been made up of fewer Oklahoma residents; however, as can be seen in the results, this was not the case. Higher educated (more than a Bachelor's degree) were $22.7 \%$ less likely to be in this segment, as were purchasers of pecans $(-27.5 \%)$. However, purchasers of cashews were $15 \%$ more likely to be in the Sugar High segment. 
Table 7. Conjoint results by segment for 8-oz package size used in a Midwestern consumer survey on nut preferences.

\begin{tabular}{|c|c|c|c|c|}
\hline & Budget Traditional & Price Sensitive & Sugar High & Cinnamon Haters \\
\hline \multicolumn{5}{|l|}{ Relative importance (\%) } \\
\hline Price per 8-oz package size & 13 & 26 & 19 & 11 \\
\hline Product type & 60 & 39 & 42 & 46 \\
\hline Product origin & 18 & 23 & 26 & 34 \\
\hline Label & 9 & 13 & 13 & 9 \\
\hline \multicolumn{5}{|l|}{ Part-worth utilities ${ }^{z}$} \\
\hline Intercept & 46.80 & 28.71 & 66.68 & 68.69 \\
\hline \multicolumn{5}{|l|}{ Price per $8 \mathrm{oz}$} \\
\hline$\$ 9.99$ & 4.87 & 8.19 & 3.90 & 2.63 \\
\hline$\$ 12.49$ & -1.61 & -2.43 & -1.07 & -0.73 \\
\hline$\$ 14.99$ & -3.26 & -5.76 & -2.83 & -1.90 \\
\hline \multicolumn{5}{|l|}{ Product type } \\
\hline Cinnamon sugar & -8.08 & -6.94 & 1.79 & -23.38 \\
\hline Chocolate-covered & -16.87 & 2.79 & 7.00 & 7.99 \\
\hline Salted and roasted & 11.84 & 1.57 & -6.55 & 3.89 \\
\hline Pralines & -13.79 & 2.31 & 3.49 & 4.89 \\
\hline Plain roasted & 26.90 & 0.27 & -5.74 & 6.61 \\
\hline \multicolumn{5}{|l|}{ Product origin } \\
\hline Oklahoma & 1.79 & 1.08 & 1.97 & 7.05 \\
\hline Georgia & 0.82 & 1.69 & 0.22 & 4.40 \\
\hline Texas & 1.21 & 0.55 & 0.89 & 4.12 \\
\hline Mexico & -5.29 & -4.17 & -4.44 & -18.49 \\
\hline USA & 1.48 & 0.84 & 1.36 & 2.92 \\
\hline \multicolumn{5}{|l|}{ Label } \\
\hline Specific Local Farm Grown & 0.55 & -0.11 & -0.28 & -0.10 \\
\hline Native American Grown & 1.11 & -0.67 & 0.51 & 1.03 \\
\hline No label & -1.67 & 0.77 & -0.24 & -0.93 \\
\hline$R$-squared (\%) & 88 & 72 & 72 & 84 \\
\hline Adjusted $R$-squared (\%) & 76 & 43 & 44 & 69 \\
\hline Respondents per segment & 65 & 143 & 209 & 93 \\
\hline Market share (\%) & 13 & 28 & 41 & 18 \\
\hline
\end{tabular}

${ }^{\mathrm{z}}$ The part-worth utilities can be thought of as the value a consumer places on each attribute level. Positive numbers represent an increase in preference, whereas negative numbers represent a decrease.

\section{Conjoint and segmentation results: 8-oz sample}

The four segments in the 8-oz sample were classified as "Budget Traditional," "Price Sensitive," "Sugar High," and "Cinnamon Haters" (Table 7). In evaluating these segments, they are similar to the $1.5-\mathrm{oz}$ results with the main difference being the Cinnamon Hater group. All four segments valued product type the most followed by either product origin or price with label last across all segments.

Budget Traditional. The Budget Traditional segment was the smallest segment at $13 \%$ of the market (Table 7). This segment attached positive utilities to salted and roasted and plain roasted nuts, while discounting cinnamon sugar, pralines, and chocolate-covered nuts. The salted and roasted nuts received a 11.84-point rating increase, whereas plain roasted had a 26.90-point rating increase on the 100-point scale. Chocolate-covered were rated 16.87 points lower followed by pralines and cinnamon sugar with 13.79 and 8.08 utility point decreases. Budget Traditional segment also valued Oklahoma products (1.79 utility increase) followed closely by USA (1.48 utility increase) and Texas (1.21 utility increase). Furthermore, this segment preferred the Native American Grown label ( 1.11 utility increase) as well as the specific local farm grown label ( 0.55 utility increase).

With respect to the demographic make-up of the segments, the Budget Traditional segment was $6.7 \%$ less likely to include high school or less-educated respondents compared with those with a Bachelor's degree (Table 8). Furthermore, this segment was less likely to be food neophobic. As the food neophobia score increased by 1 unit from the mean score, a respondent was $0.3 \%$ less likely to be in this segment. Examining nut purchasing results in the finding that purchasers of hazelnuts (Corylus avellana) were $6.3 \%$ less likely to be in this segment compared with nonpurchasers of hazelnuts. Almond purchasers were $4.9 \%$ more likely to be in this segment.

Price Sensitive. The Price Sensitive segment did not like the cinnamon sugar products but had a positive preference for all the other products (Table 7). This segment also discounted Mexican product (-4.17 utility decrease), while valuing Georgia (1.69 utility increase) and Oklahoma (1.08 utility increase). This segment was the only segment to have a positive preference for no label ( 0.77 utility increase) and a negative preference for both the specific local farm grown $(-0.11$ utility decrease) and Native American Grown ( -0.67 utility decrease) labels.

Baby Boomers and older were 12.4\% more likely than Generation X respondents to be in this segment, whereas respondents with higher food neophobia levels were $0.5 \%$ more likely to be in this segment with every 1-unit increase from the mean food neophobia level (Table 8). None of the nut purchasing variables were significant for this segment.
Sugar High. The Sugar High segment was the largest segment, making up $41 \%$ of the sample. This segment highly valued chocolate-covered nuts and pralines (Table 7). This segment was the only segment that had a positive preference for cinnamon sugar products. Notably, chocolate-covered nuts raised a respondent's utility for the product by 7 points, whereas pralines increased the utility by 3.49 points. Salted and roasted and plain roasted decreased respondent utility by -6.55 and 5.74 points, respectively. Further, this segment valued the Oklahoma origin the most (1.97 utility increase) followed by the U.S. origin (1.36 utility increase). With respect to labels, the Sugar High segment had high utility for the Native American Grown label and a negative utility for the specific local farm-grown label and no label.

Baby Boomer and older respondents were $26.8 \%$ less likely than Generation X respondents to be in this segment, as were households with a larger number of children $(-4.7 \%$ for every child above the mean) (Table 8). However, primary shoppers were $20.3 \%$ more likely to be included in this segment. Higher educated (more than a Bachelor's degree) respondents were $14.9 \%$ less likely to be in this segment, as were purchasers of peanuts $(-10.9 \%)$. However, purchasers of cashews $(10.6 \%)$ and hazelnuts were $15 \%$ more likely to be in the Sugar High segment.

Cinnamon Haters. The Cinnamon Haters segment comprised $18 \%$ of the sample. This segment had a high disdain for cinnamon sugar products (Table 7) with a 23.38-point reduction associated with a cinnamon sugar product. All other products received had a positive part-worth utility. Further, this segment valued the Oklahoma origin the most (7.05 utility increase) followed by the Georgia (4.40 utility increase), Texas (4.12 utility increase), and the USA origin (2.92 utility increase). Mexican imports were not preferred, as they received an 18.49-point lower part-worth utility. With respect to labels, the Cinnamon Haters segment had high utility for the Native American Grown label (1.03 utility increase), while being indifferent to the specific local farm-grown label $(-0.10$ utility decrease).

Baby Boomer and older respondents were $8.9 \%$ more likely than Generation X respondents to be in this segment, as were women ( $8.2 \%$ more likely than men) (Table 8$)$. However, primary shoppers were $25.3 \%$ less likely to be included in this segment. Peanut purchasers were $6.3 \%$ more likely to be in the Cinnamon Haters segment as were pecan purchasers who were $10.4 \%$ more likely.

\section{Discussion}

Pecan producers looking to add value to their crops have a multitude of options. Using a conjoint experiment with market segmentation, consumer preferences of value-added nut alternatives were gauged and suggestions for targeting specific consumer segments 
Table 8. Multinomial logit results for the 8-oz package size used in a Midwestern consumer survey on nut preferences.

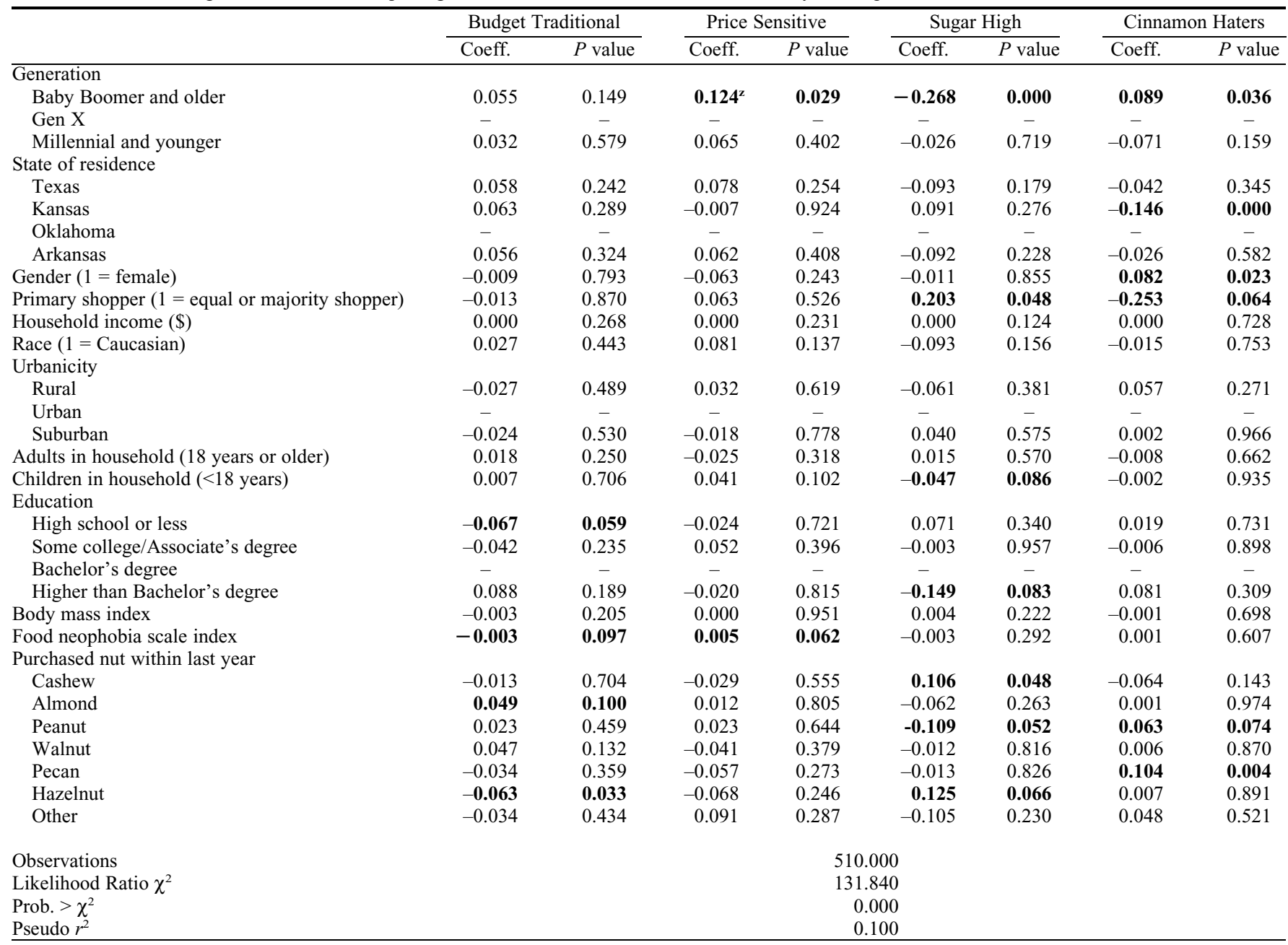

${ }^{\mathrm{z}}$ Bold denotes significance at the 0.1 level or less.

were ascertained. With respect to the smaller snack market $(1.5 \mathrm{oz})$, pecan producers would be better served focusing on the plain roasted and salted and roasted product types (i.e., Budget Traditional segment), as this segment is more likely to have purchased pecans in the recent past and is somewhat price sensitive across the two models. Pecan producers should avoid the praline, chocolate-covered, cinnamon sugar market without a sound marketing plan, as these markets are less likely to have purchased pecans. Similarly, pecan producers targeting the larger snack market $(8 \mathrm{oz}$ ) should pursue the plain roasted and salted and roasted market (i.e., Budget Traditional) as well. This segment is more likely to have purchased pecans in the recent past.

If producers decide to move outside the plain roasted and/or salted and roasted product line, they should focus on pralines and/or covered chocolate while avoiding the cinnamon sugar product type. Though there is a small market for cinnamon sugar at the $1.5-\mathrm{oz}$ and 8-oz snack sizes, a majority of the market has a negative preference for this product.

Pecan producers marketing to residents of Oklahoma, Texas, Kansas, and Arkansas should use a state origin label to identify their product as Oklahoma and Texas nut products. In addition, the Native American Grown label should be used, as it consistently outperforms the specific local farm-grown label across most market segments.

\section{Literature Cited}

Baker, G.A. and P.J. Crosbie. 1994. Consumer preferences for food safety attributes: A market segment approach. Agribusiness Intl. J. 10(4):319-324.

Baker, G.A. 1998. Strategic implications of consumer food safety preferences: Consumer concerns and willingness-to-pay. Intl. Food Agribus. Mgt. Rev. 1(4):451-463.

Baker, G.A. 1999. Consumer preferences for food safety attributes in fresh apples: Market segments, consumer characteristics, and marketing opportunities. J. Agr. Resource Econ. 24(1):80-97.

Campbell, B.L., I. Lesschaeve, A.J. Bowen, S.R. Onufrey, and H. Moskowitz. 2010. Purchase drivers of Canadian consumers of local and organic produce. HortScience 45:14801488.

Campbell, B.L., S. Mhlanga, and I. Lesschaeve. 2013. Consumer preference for peach attributes: Market segmentation analysis and implications for new marketing. Agr. Resource Econ. Rev. 42(3):518-541.

Campbell, B.L., R.G. Nelson, R.C. Ebel, and W.A. Dozier. 2006. Mandarin attributes preferred by consumers in grocery stores. HortScience $41: 664-670$
Campbell, B.L., R.G. Nelson, R.C. Ebel, W.A. Dozier, J.L. Adrian, and B.R. Hockema. 2004. Fruit quality characteristics of satsuma mandarins that affect consumer preferences. HortScience 39:1664-1669.

Darby, K., M.T. Batte, S. Ernst, and B. Roe. 2008. Decomposing local: A conjoint analysis of locally produced foods. Amer. J. Agr. Econ. 90(2):476-486.

Fields, D. and J. Gillespie. 2008. Beef producer preferences and purchase decisions for livestock price insurance. J. Agr. Appl. Econ. 40(3):789-803.

Florkowski, W.J. and T.A. Park. 2001. Promotional programmes and consumer purchasing decisions: Pecan demand models. Appl. Econ. 33(6):763-770.

Frank, C.A., R.G. Nelson, E.H. Simonne, B.K. Behe, and A.H. Simonne. 2001. Consumer preferences for color, price, and vitamin c content of bell peppers. HortScience 36:795-800.

Green, P.E. and K. Helsen. 1989. Cross-validation assessment of alternatives to individual level conjoint analysis: A case study. J. Mktg. Res. 26:346-350

Gold, M., M.M. Cernusca, and L. Godsey. 2004. Consumer preferences for chestnuts, eastern black walnuts, and pecans. HortTechnology 14:583-589.

Hair, J.F., Jr., W.C. Black, B.J. Babin, and R.E. Anderson. 2010. Multivariate data analysis. 7th ed. Prentice Hall, Upper Saddle River, NJ. 
Haire, B. 2018. Hurricane Michael changed Georgia's pecan industry. FarmProgress. 12 May 2020. <https://www.farmprogress.com/orchardcrops/hurricane-michael-changed-georgia-specan-industry $>$.

Hinds, M.J., C.M. Jolly, R.G. Nelson, Y. Donis, and E. Prophete. 2003. Comparative study of properties and acceptability of Haitian and US honey-roasted peanuts. Intl. J. Consum. Stud. 27(2):157-167.

Harrison, R.W. and P.R. Sambidi. 2004. A conjoint analysis of the U.S. broiler complex location decision. J. Agr. Appl. Econ. 36(3):639-655.

International Nut and Dried Fruit Council. 2018. Nuts and dried fruit statistical yearbook. 12 May 2020. $<$ https://www.nutfruit.org/files/tech/1553521370_ INC_Statistical_Yearbook_2018.pdf $>$.

Kotler, P. and G. Armstrong. 2001. Principles of marketing. 9th ed. Prentice Hall, Upper Saddle River, NJ.

Lillywhite, J.M., J.E. Simonsen, and R.J. Heerema. 2014. U.S. consumer purchases and nutritional knowledge of pecans. HortTechnology 24:222230.

Lin, B.H., S. Payson, and J. Wertz. 1996. Opinions of professional buyers toward organic produce: A case study of the Mid-Atlantic market for fresh tomatoes. Agribusiness Intl. J. 12(1):89-97.

Lombardini, L., T.M. Waliczek, and J.M. Zajicek. 2008. Consumer knowledge of nutritional attributes of pecans and factors affecting purchasing behavior. HortTechnology 18:481-488.

Manalo, A.B. 1990. Assessing the importance of apple attributes: An agricultural example of conjoint analysis. Northeastern J. Agr. Resources Econ. 19(2):118-124.

Moore, E.D., G.W. Williams, M.A. Palma, and L. Lombardini. 2009. Effectiveness of state-level pecan promotion programs: The case of the Texas Pecan Checkoff Program. HortTechnology 44:1914-1920.

Nelson, R.G., C.M. Jolly, M.J. Hinds, Y. Donis, and E. Prophete. 2005. Conjoint analysis of consumer preferences for roasted peanut products in Haiti. Intl. J. Consum. Stud. 29(3):208-215.

Nesbitt, M., L. Stein, and J. Kamas. 2010. Improved pecans. Texas A\&M University, AgriLIFE Extension. 12 May 2020. <https://aggie-horticulture. tamu.edu/fruit-nut/files/2010/10/improvedpecans.pdf $>$.

Onozaka, Y. and D.T. McFadden. 2011. Does local labeling complement or compete with other sustainable labels? A conjoint analysis of direct and joint values for fresh produce claims. Amer. J. Agr. Econ. 93(3):693-706.

Palma, M.A., A.J. Collart, and C.J. Chammoun. 2015. Information asymmetry in consumer perceptions of quality-differentiated food products. J. Consum. Aff. 49(3):596-612.

U.S. Census Bureau. 2019a. Age and sex. 2018: ACS 1-year estimates detailed tables, American Community Survey, Table ID:S0101. 12 May 2020 $<$ https://data.census.gov/cedsci/table?q=median $\%$ 20age\&hidePreview=true\&tid=ACSST1Y2018. S0101\& $\mathrm{t}=$ Age $\% 20$ and $\% 20$ Sex \& vintage $=2018 \&$ layer=VT_2018_040_00_PY_D1\&g=0400000 US05, 20, $48,40>$.

U.S. Census Bureau. 2019b. Median age by sex. 2018: ACS 1-year estimates detailed tables.
American Community Survey, Table ID:B01002. 12 May 2020. <https://data.census.gov/cedsci/ table? $\mathrm{q}=$ median $\% 20$ age \&hidePreview $=$ false \& tid=ACSDT1Y2018.B $1002 \& \mathrm{t}=\mathrm{Age} \% 20$ and $\% 20$ Sex \&vintage $=2018>$.

U.S. Census Bureau. 2019c. Quickfacts: Kansas; Arkansas; Texas; Oklahoma; United States. 12 May 2020. <https://www.census.gov/quickfacts/fact/table/KS,AR,TX,OK,US/PST045218>.

U.S. Department of Agriculture - Economic Research Service. 2018. Fruit and tree nut yearbook tables. 12 May 2020. <https://www.ers.usda.gov/dataproducts/fruit-and-tree-nut-data/fruit-and-treenut-yearbook-tables/\#Tree\%20Nuts>.

U.S. Department of Agriculture - Economic Research Service. 2019. Fruit and Tree Nuts Outlook. FTS-368, March, 34 p. 12 May 2020. <https://www.ers.usda.gov/webdocs/publications $/ 92731 /$ fts-368.pdf? v=7239.3 $>$.

U.S. Department of Agriculture - National Agricultural Statistics Service. 2019a. Pecan Production. 12 May 2020. $<$ https://downloads.usda.library. cornell.edu/usda-esmis/files/5425kg32f/tt44pv533/ v979v9335/pecnpr19.pdfs.

U.S. Department of Agriculture - National Agricultural Statistics Service. 2019b. Table 37. Specified fruits and nuts by acreage: 2017 and 2012. 12 May 2020. <https://www.nass.usda.gov/ Publications/AgCensus/2017/Full_Report/Volume_ 1,_Chapter_1_US/st99_1_0037_0037.pdf >

Wirth, F.F., J.L. Stanton, and J.B. Wiley. 2011. The relative importance of search versus credence product attributes: Organic and locally grown. Agr. Resource Econ. Rev. 40(1):48-62. 